\title{
A tobacco cDNA reveals two different transcription patterns in vegetative and reproductive organs
}

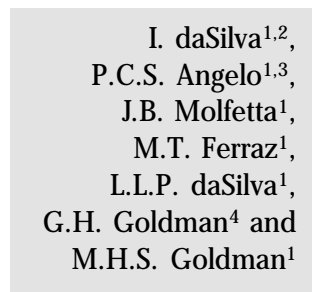

\section{Correspondence}

M.H.S. Goldman

Departamento de Biologia

FFCLRP, USP

Avenida Bandeirantes, 3900

14040-901 Ribeirão Preto, SP

Brasil

Fax: + 55-16-602-3666

E-mail: mgoldman@ ffclrp.usp.br

Research supported by FAPESP and CNPq to M.H.S. Goldman. I. daSilva, P.C.S. Angelo, J.B. Molfetta and

L.L.P. daSilva are recipients of FAPESP fellowships. M.H.S. Goldman and G.H. Goldman are recipients of Research Productivity fellowships from CNPq.

Received May 22, 2001 Accepted May 7, 2002

\author{
${ }^{1}$ Departamento de Biologia, Faculdade de Filosofia, Ciências e Letras de Ribeirão Preto, \\ Universidade de São Paulo, Ribeirão Preto, SP, Brasil \\ ${ }^{2}$ Faculdade de Ciências Agrárias e Veterinárias, \\ Universidade Estadual Júlio de Mesquita, Jaboticabal, SP, Brasil \\ ${ }^{3}$ Departamento de Genética, Faculdade de Medicina de Ribeirão Preto, \\ Universidade de São Paulo, Ribeirão Preto, SP, and Embrapa Tabuleiros Costeiros, \\ Aracaju, SE, Brasil \\ ${ }^{4}$ Departamento de Ciências Farmacêuticas, Faculdade de Ciências Farmacêuticas, \\ Universidade de São Paulo, Ribeirão Preto, SP, Brasil
}

\section{Abstract}

In order to identify genes expressed in the pistil that may have a role in the reproduction process, we have established an expressed sequence tags project to randomly sequence clones from a Nicotiana tabacum stigma/ style cDNA library. A cDNA clone (MTL-8) showing high sequence similarity to genes encoding glycine-rich RNA-binding proteins was chosen for further characterization. Based on the extensive identity of MTL-8 to the RGP-1a sequence of $N$. sylvestris, a primer was defined to extend the $5^{\prime}$ sequence of MTL-8 by RT-PCR from stigma/style RNAs. The amplification product was sequenced and it was confirmed that MTL-8 corresponds to an mRNA encoding a glycine-rich RNA-binding protein. Two transcripts of different sizes and expression patterns were identified when the MTL- 8 cDNA insert was used as a probe in RNA blots. The largest is 1,100 nucleotides (nt) long and markedly predominant in ovaries. The smaller transcript, with $600 \mathrm{nt}$, is ubiquitous to the vegetative and reproductive organs analyzed (roots, stems, leaves, sepals, petals, stamens, stigmas/styles and ovaries). Plants submitted to stress (wounding, virus infection and ethylene treatment) presented an increased level of the 600-nt transcript in leaves, especially after tobacco necrosis virus infection. In contrast, the level of the 1,100-nt transcript seems to be unaffected by the stress conditions tested. Results of Southern blot experiments have suggested that MTL-8 is present in one or two copies in the tobacco genome. Our results suggest that the shorter transcript is related to stress while the larger one is a flower predominant and nonstress-inducible messenger.

\section{Introduction}

We have established an expressed sequence tags (EST) project to randomly sequence clones from a Nicotiana tabacum (L.) stigma/style cDNA library in order to identify genes expressed in the pistil that

\section{Key words}

- Glycine-rich protein

- Nicotiana tabacum

- Pistil expression

- RNA-binding protein

- Stress conditions

- Virus infection may have a role in the pollination and fertilization processes. A cDNA clone (MTL-8) showing extensive sequence similarity to genes encoding glycine-rich RNA-binding proteins (RBP) was chosen for further characterization.

At least two groups of glycine-rich pro- 
teins from plants have been described. One of them is composed of sequences responsive to wounding and pathogen attack, stageand/or tissue-specific that have been suggested to play structural roles (1-3). The other group is a family of glycine-rich RBP that present a characteristic glycine-rich $\mathrm{C}$ terminal domain (4). This glycine-rich domain may be functional in protein-protein interactions during nuclear RNA processing and maturation (5). Nucleotide sequences coding for glycine-rich RBP have been isolated from $N$. glutinosa (4), maize (6), carrot (7), N. sylvestris $(5,8,9)$, Arabidopsis thaliana (10), and barley (11). The expression pattern for some of these sequences is influenced by a number of internal and external signals such as abscisic acid, low temperature, circadian clock and developmental processes, but mainly by stress conditions such as wounding and dehydration $(4,6,8,10)$.

We established the spatial expression pattern of MTL-8 in vegetative and reproductive organs, as well as its expression pattern in leaves submitted to stress conditions. The results demonstrated that the MTL8 probe recognizes two differentially regulated transcripts and that the level of the smaller transcript increases after infection with tobacco necrosis virus (TNV).

\section{Material and Methods}

\section{Stigma/style cDNAs for sequencing}

The construction of the $N$. tabacum (L.) stigma/style cDNA library in $\lambda$ gt10 as a vector has been described (12). Since phage DNA is more difficult to sequence, the phage clones were used to infect NM514 Escherichia coli cells, phage DNA was prepared and the cDNA inserts, obtained after $E c o$ RI digestion, were subcloned at the EcoRI site of the pUC18 plasmid vector (Amersham/Pharmacia, Uppsala, Sweden).

The cDNA inserts in the plasmid vector were sequenced by the dideoxynucleotide chain termination method (13) using the Big Dye Terminator Cycle Sequencing kit (Perkin Elmer, Foster City, CA, USA) and an ABI 377 automated sequencer (Perkin Elmer), with the M13-forward and -reverse oligonucleotides (Pharmacia, Uppsala, Sweden) as primers. The sequences obtained were compared with those registered in databases using the BLAST search program (http:// www.ncbi.nlm.nih.gov/BLAST; 14,15). Multiple sequence alignments were obtained with the Clustal W program (http:// www.ch.embnet.org/cgi-bin/clustalw_ parser).

\section{Plant material and nucleic acid manipulations}

Tobacco plants (N. tabacum cv. Petit Havana SR1) were grown under standard greenhouse conditions. Roots, stems, and leaves used for the analysis of the spatial expression pattern were collected from nonflowering plants. Sepals, petals, stamens, stigmas/styles, and ovaries represent pools of material collected at different developmental stages. All of these organs were frozen in liquid nitrogen and stored at $-70^{\circ} \mathrm{C}$ for RNA isolation.

For the analysis of plants under stress conditions, total RNA was extracted from leaves of 1-month-old plants (three plants per treatment). The effect of ethylene was examined by placing the plants in glass jars and flushing continuously with 10-ppm ethylene at a rate of $90 \mathrm{ml} / \mathrm{h}$ for $24 \mathrm{~h}$. The control plants were flushed under the same conditions, but without ethylene. For wounding experiments, leaves were extensively perforated with a forceps and collected after 24 h. Virus infection was performed by dusting the leaves with Carborundum (BDH Chemicals, Poole, UK), inoculating with purified $\mathrm{TNV}$, which was diluted to $1 \mu \mathrm{g} / \mathrm{ml}$ in inoculation buffer ( $10 \mathrm{mM}$ sodium phosphate, $\mathrm{pH}$ 7.0), and rinsing with water. These plants were grown for an additional 12 days. The 
respective controls were plants kept under the same environmental conditions as the treated plants (16).

Total RNA was extracted essentially as described by Dean et al. (17). Genomic DNA was isolated from tobacco leaves for Southern analysis, following the procedure of Dellaporta et al. (18). To quantify the amount of DNA and RNA, absorbance measurements were made at 260 and $280 \mathrm{~nm}$ using a GeneQuant instrument (Pharmacia). Plasmid DNA preparation, digestion with restriction enzymes, electrophoretic separation and other standard procedures were carried out using the protocols described by Sambrook et al. (19).

For RT-PCR, $1 \mu \mathrm{g}$ of stigma/style total RNA was used as a template for reverse transcription using $500 \mathrm{ng}$ of oligo(dT) ${ }_{12-18}$ primer (Promega, Madison, WI, USA) and 200 U of the Superscript II enzyme (Gibco BRL, Rockville, MD, USA) for $50 \mathrm{~min}$ at $42^{\circ} \mathrm{C}$. The following PCR was performed with a $2-\mu l$ aliquot of the first strand cDNA in a final volume of $50 \mu \mathrm{l}$ and $10 \mathrm{pmol}$ of each specific primer (MTL-8F: 5'-GG TTTCTTCTTATTAATTAGG-3' and MTL8R:5'-TAACATCACGGTAACAATCTC-3'). The reaction was carried out with $0.5 \mu$ of Taq DNA polymerase (Gibco) in the thermal cycler programmed as follows: initial step for denaturation of DNA fragments, 3 min at $95^{\circ} \mathrm{C}$; 40 cycles, $1 \mathrm{~min}$ at $95^{\circ} \mathrm{C}$ for denaturation, 2 $\mathrm{min}$ at $48^{\circ} \mathrm{C}$ for annealing, $4 \mathrm{~min}$ at $72^{\circ} \mathrm{C}$ for polymerization, followed by the final elongation step, $10 \mathrm{~min}$ at $72^{\circ} \mathrm{C}$.

\section{Nucleic acid hybridization}

Total RNA was denatured, size fractionated on $1.5 \%(\mathrm{w} / \mathrm{v})$ agarose-formaldehyde gel, transferred to nylon filters (Hybond $\mathrm{N}^{+}$, Amersham) and fixed by UV irradiation and baking. A 272-bp EcoRI fragment of the MTL-8 cDNA insert, purified from agarose gel and labeled with $\left[\alpha-{ }^{32} \mathrm{P}\right]-\mathrm{dCTP}$ using the Random Primers DNA Labeling System
(Gibco BRL), was used as a probe. Hybridization was performed in $6 \times \mathrm{SSC}, 5 \mathrm{x}$ Denhardt's solution, $0.5 \%$ SDS, and $100 \mu \mathrm{g} /$ $\mathrm{ml}$ denatured carrier DNA, at $50^{\circ} \mathrm{C}$ overnight. Filters were washed in solutions with decreasing salt concentrations: $6 \times \mathrm{SSC} / 0.5 \%$ SDS, $2 \times \mathrm{SSC} / 0.1 \% \mathrm{SDS}, 1 \times \mathrm{SSC} / 0.1 \%$ SDS, $0.5 \times \mathrm{SSC} / 0.1 \% \mathrm{SDS}$ and $0.1 \times \mathrm{SSC} /$ $0.1 \% \mathrm{SDS}$, for $30 \mathrm{~min}$ each at $50^{\circ} \mathrm{C}$.

Tobacco genomic DNA $(10 \mu \mathrm{g})$ was digested with restriction enzymes, separated by electrophoresis on $1 \%$ agarose gels, transferred to nylon filters (Hybond $\mathrm{N}^{+}$, Amersham) and hybridized to the radioactively labeled MTL-8 probe (see above). Hybridization and washings were performed as described for the RNA blot, but at $65^{\circ} \mathrm{C}$.

\section{Results}

\section{MTL-8 encodes a putative glycine-rich RNA-binding protein}

The MTL- 8 cDNA insert was completely sequenced and its nucleotide and deduced amino acid sequences are shown in Figure 1. MTL-8 has 272 nucleotides (nt) and is a partial cDNA. It encodes the carboxyl-terminus of a protein that is composed mainly of glycine (8 glycines in 18 amino acid residues). A stop codon and a putative polyadenylation signal are present at positions 55 and 220, respectively. There is a poly(A)-tail starting at position 247 (Figure 1). Searches for similarities in the databases (http:// www.ncbi.nlm.nih.gov/BLAST; 14,15) have demonstrated the high level of identity $(91 \%)$ between the MTL- 8 sequence and the sequence encoding the carboxyl-terminus of a glycine-rich RBP (RGP-1a) from $N$. sylvestris (8). This identity extended through the 3 '-untranslated region (Figure 1), which is generally a less conserved sequence due to lower selective pressure. Since N. tabacum is an allotetraploid thought to be derived from ancestors of $N$. sylvestris and $N$. tomentosiformis (20), this sequence similarity 
strongly suggests that MTL- 8 is the true homologue of RGP-1a.

Because on the identity between MTL-8 and RGP-1a, we used the RGP-1a sequence to define a primer to extend the 5 ' region of MTL-8 (see MTL-8F in Material and Methods and Figure 1). The first strand cDNA was prepared from stigma/style total RNA, using an oligo(dT) as primer, and was subsequently used in a PCR with two specific primers (the one mentioned above and one with a sequence from the MTL-8 3'-untranslated region, MTL-8R) at a relatively low annealing temperature $\left(48^{\circ} \mathrm{C}\right)$. This RT-PCR resulted in a single band of approximately $600 \mathrm{bp}$. Sequencing demonstrated perfect

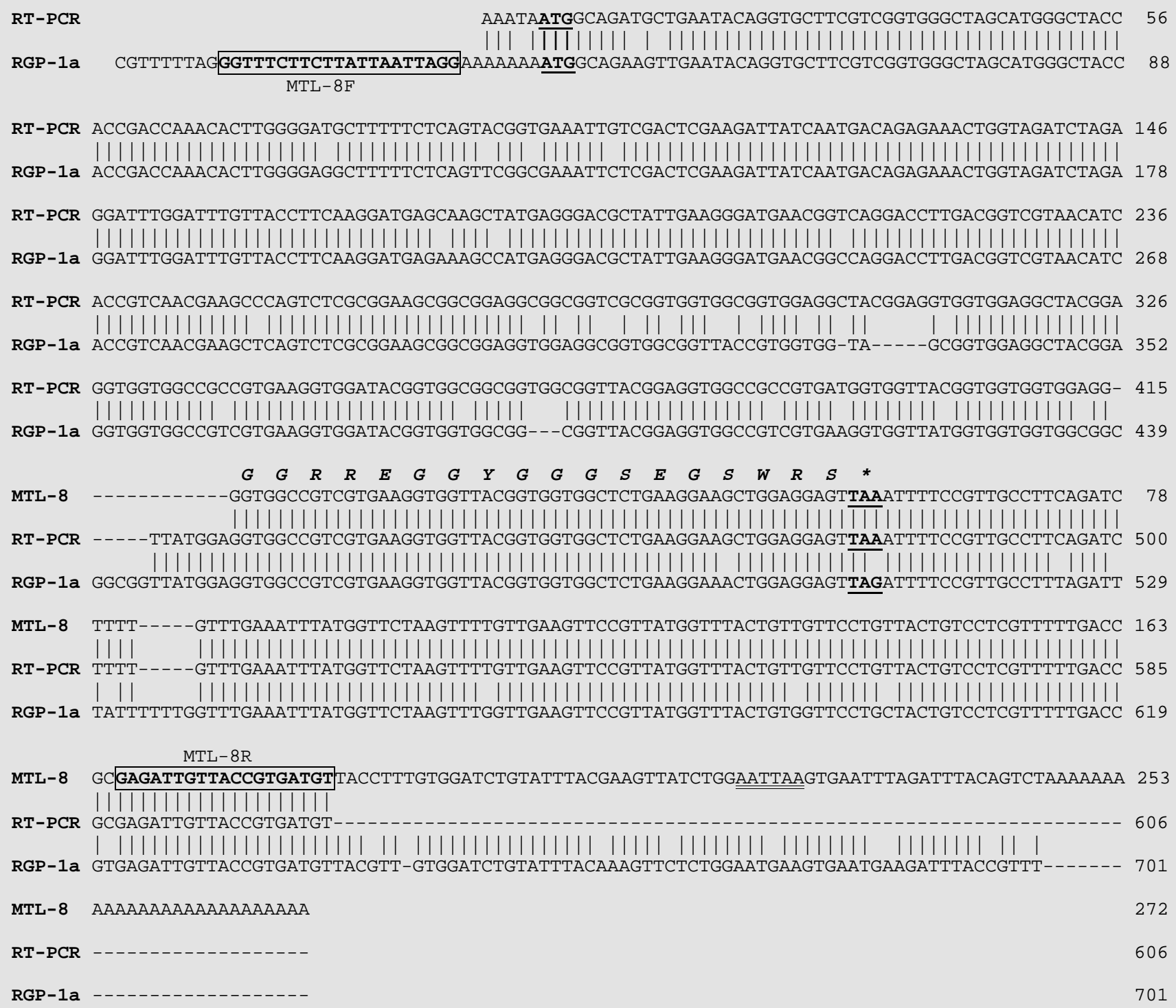

Figure 1. Alignment of the nucleotide sequences of MTL-8 CDNA, the RT-PCR fragment and glycine-rich RNA-binding protein (RGP-1a) from Nicotiana sylvestris (accession number D16024). Vertical bars indicate identical nucleotides and dashes indicate gaps introduced to obtain the best alignment. The translation start and termination codons are shown in bold underlined letters, and the putative polyadenylation signal is underlined twice. The deduced amino acid sequence of the MTL-8 cDNA clone appears in bold italic letters above the MTL- 8 nucleotide sequence. The sequences corresponding to the MTL-8F and MTL-8R primers are shown in bold letters inside boxes. 
identity with the MTL- 8 cDNA insert (Figure 1). In addition, the RT-PCR fragment showed $90.4 \%$ identity to RGP-1a at the nucleotide level.

Figure 2 presents a comparison of the amino acid sequences of the MTL-8 RTPCR fragment, the RBP from $N$. glutinosa (4) and three glycine-rich RBP from $N$. sylvestris (8). The nucleotide differences between MTL-8 and RGP-1a resulted in few modifications in the encoded protein sequence, most of them involving amino acids with similar chemical characteristics. Like the three RGP-1 (a, b and c) proteins (8), MTL-8 contains an RNA recognition motif in the N-terminal half and a glycine-rich domain in the C-terminal half (Figure 2). The RNA recognition motif is usually diagnostic of an RBP since it is found in a variety of RBP. The motif also appears in a few single-stranded DNA-binding proteins. However, RGP-1 a has been experimentally proven to bind RNA.

\section{MTL-8 identifies two different transcripts in vegetative and reproductive organs}

In an attempt to determine the spatial expression pattern of the gene corresponding to MTL-8 cDNA, we performed a Northern analysis with $15 \mu \mathrm{g}$ of total RNA extracted from roots, stems, leaves, sepals, petals, stamens, stigmas/styles, and ovaries. The MTL- 8 probe revealed two different transcripts: one with $600 \mathrm{nt}$ and a second one with 1,100 nt. The 600-nt transcript was present in all the organs investigated. Its steady state level seemed to be higher in roots, stems, sepals, petals, stigmas/styles and ovaries, and lower in leaves and stamens (anthers and filaments) (Figure 3$)$. In contrast, the 1,100-nt transcript was present at high level in ovaries, and at lower levels in sepals, stigmas/styles and roots. Faint hybridization signals were also demonstrable in stems, leaves, petals and stamens (Figure 3).

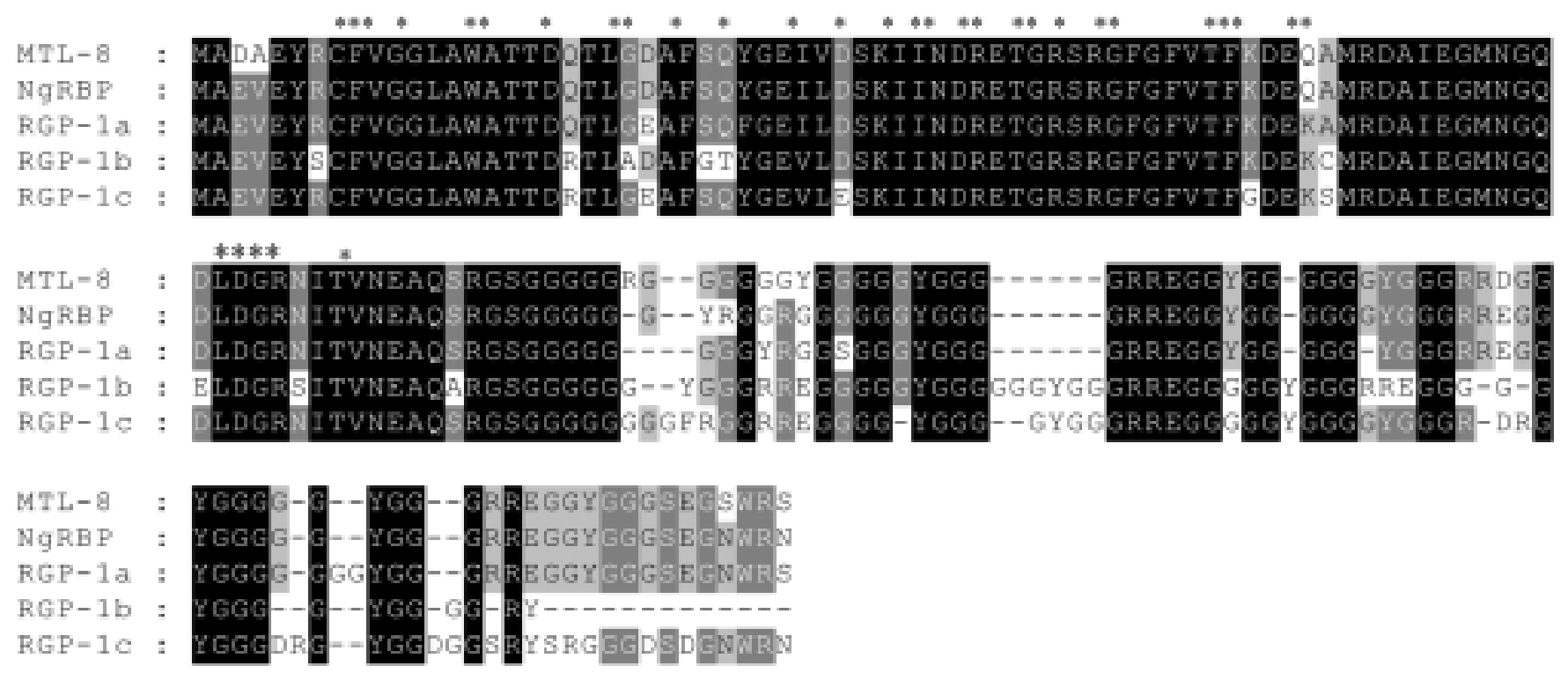

Figure 2. Alignment of the amino acid sequences corresponding to the MTL-8 RT-PCR fragment, a Nicotiana glutinosa RNA-binding protein (NgRBP) (accession number AF005359) and three glycine-rich RNA-binding proteins from N. sylvestris (RGP-la, RGP-1b and RGP-1c, accession numbers D16204, D16205 and D16206, respectively). Alignment was obtained with the Clustal W program (http://www.ch.embnet.org/cgi-bin/clustalw_parser). Black boxes indicate consenved amino acids in all proteins, dark gray boxes indicate conserved amino acids in four proteins, and light gray boxes conserved amino acids in three proteins. The amino acids relevant to the RNA recognition motif are marked with asterisks. 
Figure 3. A, RNA blot analysis showing the accumulation of MTL-8 transcripts in the different vegetative and reproductive organs of Nicotiana tabacum. Total RNA $(15 \mu \mathrm{g})$ from each identified sample was loaded per lane: $R$, roots; S, stems; L, leaves; Se, sepals; $P$, petals; $A$, anthers and filaments (stamens); St, stigmas/ styles; O, ovaries. The final wash was done in $0.1 \times \mathrm{SSC} / 0.1 \% \mathrm{SDS}$, for $30 \mathrm{~min}$ at $50^{\circ} \mathrm{C}$. B, The same blot as in A, hybridized to a ribosomal RNA probe used as control for the nucleic acid concentration in the different lanes. $\mathrm{nt}=$ nucleotides

Figure 4. A, RNA blot analysis showing the accumulation of MTL-8 transcripts in leaves from Nicotiana tabacum plants submitted to different stress conditions. Total RNA (15 $\mu \mathrm{g})$ from each identified sample was loaded per lane: CW, control of wounding; W, wounding; CV, control of tobacco necrosis virus infection; $\mathrm{V}$, tobacco necrosis vi-

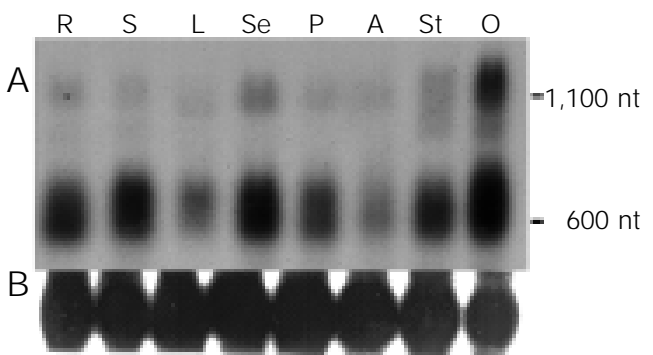
rus infection; $C E$, control of the ethylene treatment; $E$, ethylene treatment; St, stigmas/ styles, used as a control $(10 \mu \mathrm{g})$. The final wash was done in 1 x SSC/0.1\% SDS, for $30 \mathrm{~min}$ at $50^{\circ} \mathrm{C}$. B, The same blot as in A, hybridized to a ribosomal RNA probe used as control for the nucleic acid concentration in the different lanes. nt = nucleotides.

Figure 5. Genomic DNA of Nicotiana tabacum digested with restriction enzymes, separated by electrophoresis, transferred to Hybond $\mathrm{N}^{+}$filters and hybridized to the MTL-8 cDNA clone as a probe. The final wash was $0.1 \mathrm{x}$ $\mathrm{SSC} / 0.1 \% \mathrm{SDS}, 30 \mathrm{~min}$, at $65^{\circ} \mathrm{C}$.
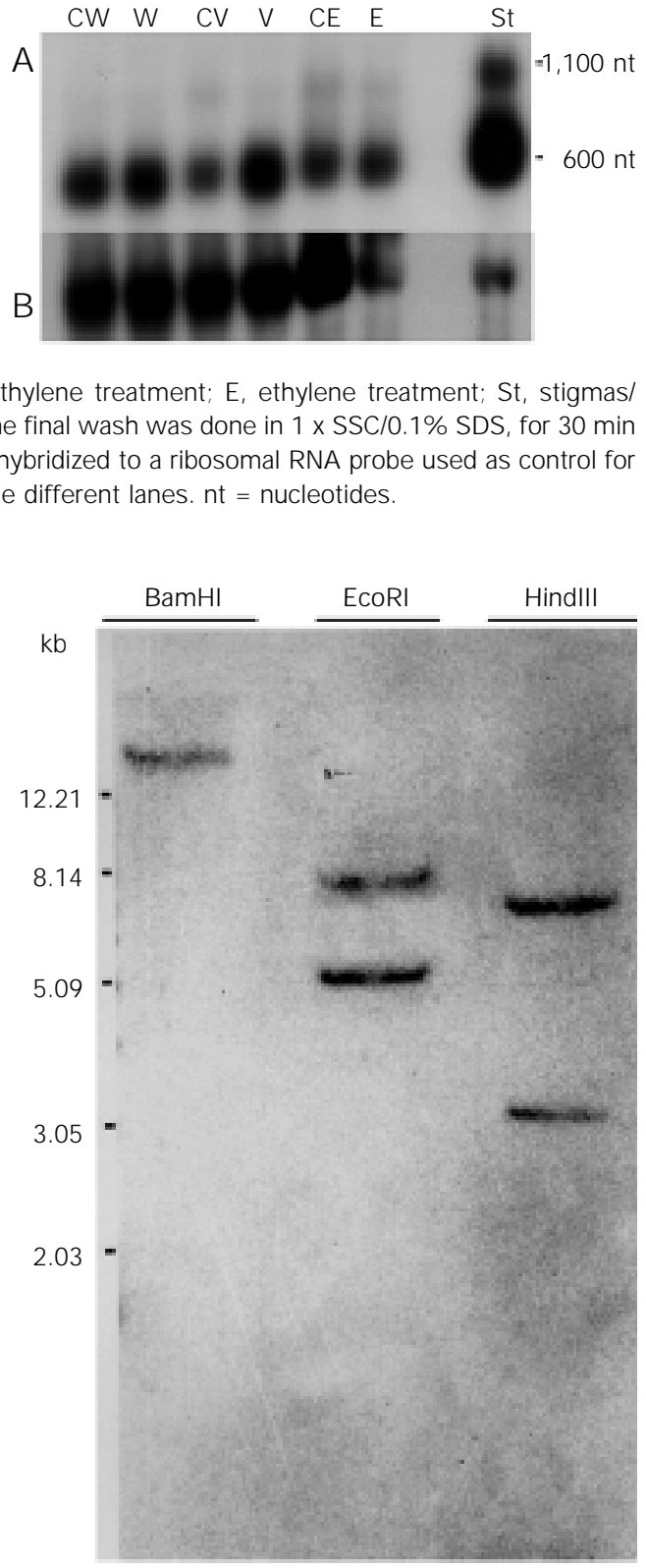

\section{Tobacco necrosis virus infection increases the level of the $600-n t$ transcript}

Due to the well-documented stress inducibility of glycine-rich RBP $(4,6,7)$, we determined whether MTL-8 expression would be induced in vegetative tissues of plants under stress conditions. Therefore, we performed an RNA blot analysis with leaf RNA extracted from plants submitted to wounding, TNV infection and ethylene treatment. There were interesting differences between the expression control mechanisms acting on the two transcripts (Figure 4). Following TNV infection, there was a clear increase in the steady-state mRNA level of the 600-nt transcript in leaves. It seems that wounding and ethylene were also able to stimulate the accumulation of the shorter transcript, but the induction was not so pronounced. Conversely, the 1,100-nt transcript remained almost undetectable in leaves and was not affected by the stress conditions tested (Figure 4), demonstrating that there is differential regulation of the 600- and 1,100nt transcripts.

\section{Few sequences related to MTL-8 are present in the $\mathrm{N}$. tabacum genome}

A Southern blot analysis using $N$. tabacum genomic DNA was performed under high stringency conditions (final wash in $0.1 \mathrm{x}$ $\mathrm{SSC} / 0.1 \% \mathrm{SDS}$, for $30 \mathrm{~min}$, at $65^{\circ} \mathrm{C}$ ) and one or two bands hybridized to MTL-8 in the $N$. tabacum genome (Figure 5), depending on the restriction enzyme digestion used. Similar findings were reported for glycine-rich RBP found in carrot (7), A. thaliana (10) and $N$. sylvestris (9). It is possible that for $N$. tabacum, an allotetraploid species, MTL-8 corresponds to a single copy gene, represented in both ancestral genomes ( $N$. sylvestris and $N$. tomentosiformis) (20) by slightly divergent sequences. Another possibility is that EcoRI and HindIII sites are present in the unique MTL-8 genomic sequence. There- 
fore, it seems that small gene families or unique genes encode these proteins in different plant species.

\section{Discussion}

The high nucleotide identity (91\%) between MTL-8 and RGP-1a from N. sylvestris extended through the 3'-untranslated region (Figure 1), usually a less conserved sequence, suggesting that MTL- 8 is the true homologue of RGP-1a. This high identity led us to develop a strategy to obtain the full-length coding region corresponding to MTL-8. RTPCR was performed using stigma/style total RNA and a primer derived from the RGP-1a sequence (see Material and Methods and Figure 1). Despite the difference in mRNA abundance between the 600- and the 1,100nt transcripts, it was expected that two bands would be generated by this approach, one from each transcript. However, a single band of approximately $600 \mathrm{bp}$ resulted from this reaction and its sequence confirmed its identity to RGP-1a (8) and to $N$. glutinosa RBP (4). This observation could be explained if the sequence chosen for the MTL-8F primer were not present in the 1,100-nt transcript. Different transcript sizes can be produced by different transcription start sites, alternative splicing or different polyadenylation sites within a single gene, and the first two possibilities could generate transcripts lacking the MTL-8F sequence. Another explanation is that the MTL-8 probe cross-hybridized with the 1,100-nt transcript that is the product of a second gene and consequently does not have the same 5 ' sequence. This would occur if the two genes shared a similar exon (the sequence of the MTL- 8 cDNA), as a result of exon shuffling (21). However, it is unlikely that the MTL- 8 probe cross-hybridized with transcripts from independent but similar genes under the conditions used in these experiments. On the other hand, alternative splicing within a single gene can explain the existence of two RNA transcripts. The fact that several genes encoding glycine-rich RBP produce transcripts by alternative splicing strongly supports this last hypothesis. This was found to be true for RGP-1a from $N$. sylvestris, which produces transcripts with 700 and $1,100 \mathrm{nt}$.

We showed that the steady-state mRNA level of the 600-nt transcript is responsive to stress conditions and accumulates after TNV infection (Figure 4). Similarly, transcription of an $N$. glutinosa glycine-rich RBP gene was induced in plants infected with tobacco mosaic virus (4). In Arabidopsis, two cDNAs encoding glycine-rich RBP with a possible role in RNA transcription or processing during stress have been described (22). Taken together, these results suggest that the shorter MTL-8 transcript might encode a protein involved in the biosynthesis, processing or translation of mRNAs responsive to stress conditions, particularly virus infection. On the other hand, the 1,100-nt transcript was not demonstrable in leaves from plants under stress (Figure 4). Therefore, this longer transcript might code for a protein with a role in processes occurring predominantly in ovaries and related to plant sexual reproduction. Poly(A)-binding proteins that may regulate plant sexual reproduction, affecting mRNA stability and/or translation, have been described (23). In addition, there are at least two RNA-binding proteins (FCA and FPA) involved in floral induction $(24,25)$ and one (HUA1) that regulates stamen and carpel identities (26) in Arabidopsis.

\section{Acknowledgments}

We thank Sônia M. da Silva for technical assistance and Leonardo A.G. Pileggi, Thais F.S. Ribeiro, Maria F. Terenzi, Andrea C. Quiapin and Patrícia M. Vitorelli for helping in different stages of the experiments. We also thank SEITA (Bergerac, France) for providing Nicotiana seeds. 


\section{References}

1. Keller B, Sauer N \& Lamb CJ (1988). Glycine-rich cell wall proteins in bean: gene structure and association of the protein with the vascular system. EMBO J oumal, 7: 3625-3633.

2. Fang RX, Pang Z, Gao D-M, Mang K-Q \& Chua N-H (1991). cDNA sequence of a virus-inducible, glycine-rich protein from rice. Plant Molecular Biology, 17: 12551257.

3. Lei M \& Wu R (1991). A novel glycine-rich cell wall protein in rice. Plant Molecular Biology, 16: 186-198.

4. Naqvi SMS, Park K-S, Yi S-Y, Lee H-W, Bok SH \& Choi D (1998). A glycine-rich RNA-binding protein gene is differentially expressed during acute hypersensitive response following tobacco mosaic virus infection in tobacco. Plant Molecular Biology, 37: 571-576.

5. Li Y \& Sugiura M (1990). Three distinct ribonucleoproteins from tobacco chloroplasts: each contains a unique amino terminal acidic domain and two ribonucleoprotein consensus motifs. EMBO J ournal, 9: 3059-3066.

6. Gómez J, Sanchez-Martínez D, Stiefel V, Rigau $J$, Puigdomènech $P \&$ Pagès $M$ (1988). A gene induced by the plant hormone abscisic acid in response to water stress encodes a glycine-rich protein. $\mathrm{Na}-$ ture, 334: 262-264.

7. Sturm A (1992). A wound-inducible glycine-rich protein from Daucus carota with homology to single-stranded nucleic acidbinding proteins. Plant Physiology, 99: 1689-1692.

8. Hirose T, Sugita M \& Sugiura M (1993). cDNA structure, expression and nucleic acid-binding properties of three RNA-binding proteins in tobacco: occurrence of tissue-specific alternative splicing. Nucleic Acids Research, 21: 3981-3987.

9. Moriguchi $K$, Sugita $M \&$ Sugiura $M$
(1997). Structure and subcellular localization of a small RNA-binding protein from tobacco. Plant J oumal, 12: 215-221.

10. Carpenter $C D$, Kreps J A \& Simon $A E$ (1994). Genes encoding glycine-rich Arabidopsis thaliana proteins with RNA-binding motifs are influenced by cold treatment and an endogenous circadian rhythm. Plant Physiology, 104: 1015-1025.

11. Dunn MA, Brown K, Lightowlers R \& Hughes MA (1996). A low-temperatureresponsive gene from barley encodes a protein with single-stranded nucleic acidbinding activity, which is phosphorylated in vitro. Plant Molecular Biology, 30: 947959.

12. Goldman MHS, Pezzotti M, Seurinck J \& Mariani C (1992). Developmental expression of tobacco pistil-specific genes encoding novel extensin-like proteins. Plant Cell, 4: 1041-1051.

13. Sanger F, Nicklen $S \&$ Coulson AR (1977). DNA sequencing with chain-terminating inhibitors. Proceedings of the National Academy of Sciences, USA, 74: 54635467.

14. Altschul SF, Gish W, Miller W, Myers EW \& Lipman DJ (1990). Basic local alignment search tool. J ournal of Molecular Biology, 215: 403-410.

15. Altschul SF, Madden TL, Schaffer AA, Zhang J U, Zhang Z, Miller W \& Lipman DJ (1997). Gapped BLAST and PSI-BLAST: a new generation of protein database search programs. Nucleic Acids Research, 25: 3389-3402.

16. Goldman MHS, Seurinck J, Marins M, Goldman GH \& Mariani C (1998). A tobacco flower-specific gene encodes a polyphenol oxidase. Plant Molecular Biology, 36: 479-485.

17. Dean $C$, Van der Elzen $P$, Tamaki $S$, Dunsmuir P \& Bedbrook J (1985). Differential expression of the eight genes of the petunia ribulose bisphosphate carboxylase small subunit multi-gene family. EMBO J ournal, 4: 3055-3061.

18. Dellaporta SL, Wood J \& Hicks J B (1983) A plant DNA minipreparation: version II. Plant Molecular Biology Reports, 1: 1927.

19. Sambrook J, Fritsch EF \& Maniatis $T$ (1989). Molecular Cloning, A Laboratory Manual. 2nd edn. Cold Spring Harbor Laboratory, New York, NY, USA.

20. Lim KY, Matyasek R, Lichtenstein CP \& Leitch AR (2000). Molecular cytogenetic analyses and phylogenetic studies in the Nicotiana section Tomentosae. Chromosoma, 109: 245-258.

21. Dorit RL, Schoenbach L \& Gilbert $W$ (1990). How big is the universe of exons? Science, 250: 1377-1382.

22. Van Nocker S \& Vierstra RD (1993). Two cDNAs from Arabidopsis thaliana encode putative RNA binding proteins containing glycine-rich domains. Plant Molecular Biology, 21: 695-699.

23. Palanivelu R, Belostotsky DA \& Meagher RB (2000). Conserved expression of Arabidopsis thaliana poly(A) binding protein 2 (PAB2) in distinct vegetative and reproductive tissues. Plant J oumal, 22: 199210.

24. Koornneef M (1997). Plant development: Timing when to flower. Current Biology, 7: 651-652.

25. Schomburg FM, Patton DA, Meinke DW $\&$ Amasino RM (2001). FPA, a gene involved in floral induction in Arabidopsis, encodes a protein containing RNA-recognition motifs. Plant Cell, 13: 1427-1436.

26. Li J , J ia D \& Chen X (2001). HUAl, a regulator of stamen and carpel identities in Arabidopsis, codes for a nuclear RNA binding protein. Plant Cell, 13: 2269-2281. 